\title{
Regulation of the elemental composition of the epididymal fluids in the tammar, Macropus eugenii
}

\author{
R. C. Jones and J. Clulow \\ Department of Biological Sciences, University of Newcastle, New South Wales 2308, Australia
}

\begin{abstract}
Summary. Micropuncture, microanalytical and microelectrode techniques were used to study electrochemical aspects of 7 elements and fluid in the ductuli efferentes and ductus epididymidis of the tammar. Rete testis fluid was isosmotic with blood and had a lower $\mathrm{pH}$. It also contained lower concentrations of bicarbonate, sodium, calcium, magnesium, phosphorus and sulphur and higher concentrations of potassium and chloride than blood. The luminal fluid was acidified further during passage through the sperm ducts and all of the elements which were studied moved in or out of the lumen, usually against an electrochemical gradient. The ductuli efferentes reabsorbed $87 \%$ of the fluid leaving the testis without changing the intraluminal concentrations of sodium, potassium and calcium, but the concentrations of magnesium, phosphorus and sulphur increased. The caput epididymidis reabsorbed about half the fluid entering it: sodium concentrations decreased and those of potassium and phosphorus increased. There was also some fluid reabsorption and an increase in the values of potassium and phosphorus in the corpus epididymidis. There was little net transport of fluid in the cauda epididymidis; sodium, chloride, magnesium and phosphorus concentrations decreased and potassium values increased.

Studies involving filtration through a dialysis membrane of blood and fluid from the rete testis and cauda epididymidis showed that, whilst some of the calcium, magnesium, phosphorus and sulphur was associated with high molecular weight compounds in blood, the association was not significant in the reproductive fluids.

It is concluded that, except for chloride, the concentrations of the elements vary along the epididymis of the tammar in a way similar to (but different in magnitude) the pattern described for eutherians like the rat. However, the tammar does not accumulate as much organic material in the duct lumen as does the rat and little is present in the cauda epididymidis.
\end{abstract}

\section{Introduction}

Although it is recognized that the mammalian epididymis is involved in sperm maturation and storage (Orgebin-Crist, 1975; Bedford, 1975) the role it plays in these processes is not understood. Biochemical analyses of the epididymal luminal fluids in the ram (Scott et al., 1963), bull (Crabo \& Gustafson, 1964; Wales et al., 1966), boar (Crabo, 1965) and African elephant (Jones, 1980) provided details of the highly specialized and changing milieu to which spermatozoa are exposed during passage through the epididymis. However, these studies did not assess the mechanisms of fluid and ion transport across the duct mucosa and the validity of their data is open to question as the samples were collected from post-mortem material using fairly crude methods which could allow contamination of the samples with other fluids. Levine \& Marsh (1971) and Levine \& Kelly (1978) avoided these criticisms by using the micropuncture, microanalytical and microelectrode procedures of kidney physiologists. They showed that the epididymal mucosa in the rat is involved in a complex pattern of secretion and reabsorption with apparently different mechanisms operating 
in each of the epididymal regions which were studied. Subsequently, Jenkins et al. (1980) extended the work on the inorganic composition of the luminal milieu in the rat by using electron probe microanalysis to determine, in fluid volumes of $<50 \mathrm{pl}$, the concentrations of elements with atomic numbers above 5 . However, there have been no similar studies on other mammals.

In the micropuncture studies mentioned above, sampling sites were not selected in relation to the structural differentiation of the epididymis (Reid \& Cleland, 1957; Nicander \& Glover, 1973) and in particular, the initial segment was not sampled for inorganic analyses as its long stereocilia occlude the lumen and contaminate micropuncture samples (see Jones, 1987). Consequently, interpretation of the roles of the efferent ducts and initial segment of the epididymis have been confounded even though these regions have quite different functions (Jones, 1980, 1987; Djakiew \& Jones, 1983). These problems have been avoided in the present study with the tammar, an Australian marsupial, which has relatively short stereocilia on the epididymal epithelium (Jones et al., 1984) that can be micropunctured anywhere along its length (Jones, 1987).

\section{Materials and Methods}

Animals. Mature, male tammars weighing $6 \cdot 0-7.6 \mathrm{~kg}$ were obtained from a colony bred at 'Gungahlin', Canberra, A.C.T., from stock originally collected from Kangaroo Island, South Australia.

Collection of micropuncture samples. All of the samples of luminal fluid were collected directly into micropuncture pipettes using the methods described in an earlier report (Jones, 1987). Samples were collected from the rete testis, proximal and distal caput, distal corpus and distal cauda epididymidis. The sampling sites in the epididymis correspond to regions 1, 8, 18 and 22 respectively in Fig. 1 of Jones et al. (1984).

Fluid transport, $p H$, bicarbonate concentration and osmolalities. Values for fluid reabsorption (see Jones, 1987) are given in Table 1 to help interpret the significance of changes in the intraluminal concentration of electrolytes. Osmolalities were measured with a Clifton Nanolitre Osmometer (Clifton Technical Physics, Hartford, NY, U.S.A.). $\mathrm{pH}$ values were determined in an atmosphere containing $5 \%$ carbon dioxide immediately after the samples were collected. The $\mathrm{pH}$ meter (Metrohin, Herisau, Switzerland) was fitted with a micro-combination pH probe (Model M1-410; Microelectrodes Inc., Londonderry, NH, U.S.A.). Bicarbonate concentrations were calculated using the form of the Henderson-Hasselbalch equation described by Levine \& Marsh (1971).

Elemental analysis. The concentration of elements in the micropuncture samples of luminal fiuid was measured by electron probe microanalysis (Rick et al., 1977) using a TN 5500 energy-dispersive X-ray analyser (Tracor, Northern, Middleton, WI, U.S.A.) attached to a JSM 840 scanning electron microscope (Jeol, Tokyo, Japan). All values were corrected to compensate for interference caused by the presence of protein in the samples (J. Clulow \& R.C. Jones, unpublished data).

To determine whether elements were bound to a large molecular weight compound some samples (Table 3) were filtered through a Cuprophan dialysis membrane (pore diameter $46 \mathrm{~nm}$, Technicon Instruments, NY, U.S.A.) using the apparatus described by Morel et al. (1969).

Electrical potentials and electrochemical gradient. Electrical potentials across the duct mucosa were measured using glass microelectrodes filled with $3 \mathrm{M}-\mathrm{KCl}$ connected via silver-silver chloride half cells to a high-impedance voltmeter and a $3 \mathrm{M}-\mathrm{KCl}$-agar polyethylene tube inserted subcutaneously as a reference electrode (Tuck et al., 1970; Levine \& Marsh, 1971). There was an abrupt deflection of the recording pen within 3-10 sec of penetrating the duct with the electrode and then it gradually returned to zero over 0.5 to $2 \mathrm{~min}$. The gradual return was due to leakage of potassium from the wide electrode tip $(2-5 \mu \mathrm{m})$ which was necessary to penetrate the muscular tunic of the duct. The direction and magnitude of the electrochemical gradient for each electrolyte was determined by comparing the measured electrical potential across the duct mucosa with an estimate of the equilibrium electrical potential calculated for the electrolyte using the Nernst equation (Levine \& Marsh, 1971). Transport of an ion against its electrochemical gradient was considered to be active and transport down its gradient was considered to be passive.

Analyses of data. Data are presented as means \pm standard errors. The standard errors were calculated from the variance between animals and this variance was also used for statistical tests of significance. Two statistical tests were carried out to determine the consequences of fluid and salt transport across the epididymal mucosa between two adjacent sampling sites. The significance of changes in the milieu were assessed using an F-test comparing the intraluminal concentrations of an element. As the intraluminal milieu can be modified by water and/or solute transport across the epididymal mucosa, the effect of just water transport on the concentration of solute was also determined using an F-test comparing the measured mean elemental concentration at the distal site with a theoretical value. The latter was an estimate of the expected concentration of the element resulting from net fluid transport across the mucosa between the sites, but no transport of this element under consideration. The estimate was calculated using the formula: $\mathrm{C}_{2}=\mathrm{C}_{1} \cdot \mathrm{S}_{2} / \mathrm{S}_{1}$ where $\mathrm{C}$ indicates concentration of the element, $\mathrm{S}$ indicates spermatocrit values and the subscripts 1 and 2 refer to the proximal and distal sites respectively. 
Table 1. Reabsorption of fluid from duct lumen, osmolality, $\mathrm{pH}$ and bicarbonate concentration of luminal fluid, and electrical potential difference of lumen relative to bathing medium

\begin{tabular}{|c|c|c|c|c|c|c|}
\hline \multirow[b]{2}{*}{ Site* } & \multirow{2}{*}{$\begin{array}{c}\text { Fluid } \\
\text { reabsorption } \ddagger \\
(\%)\end{array}$} & \multicolumn{2}{|c|}{ Osmolalities (mosmol/kg) } & \multirow{2}{*}{$\begin{array}{l}\text { Potential } \\
\text { difference } \\
(\mathrm{mV})\end{array}$} & \multirow[b]{2}{*}{$\mathrm{pH}_{\dagger}^{\dagger}$} & \multirow{2}{*}{$\begin{array}{l}\text { Bicarbonate } \\
\text { (mM) }\end{array}$} \\
\hline & & Measured & Difference & & & \\
\hline No. of tammars & 6 & 5 & & 5 & 7 & 7 \\
\hline Blood plasma & - & $288 \pm 3 \cdot 2$ & 39 & - & $7.49 \pm 0.05$ & $29 \pm 3 \cdot 5$ \\
\hline Rete testis & - & $296 \pm 2 \cdot 6$ & 32 & - & $7.00 \pm 0.03^{\mathrm{a}}$ & $10 \pm 0 \cdot 6^{a}$ \\
\hline \multicolumn{7}{|l|}{ Epididymis } \\
\hline Proximal caput (1) & $87^{\mathrm{a}}$ & $288 \pm 3 \cdot 2$ & 77 & $-7.9 \pm 1.2$ & - & - \\
\hline Distal caput (8) & $78^{\mathrm{a}}$ & $323 \pm 5 \cdot 2^{\mathrm{a}}$ & 130 & $-7.7 \pm 0.5$ & - & - \\
\hline Distal corpus (18) & $27^{\mathrm{b}}$ & $319 \pm 7.2$ & 121 & $-8.1 \pm 0.7$ & - & - \\
\hline Distal cauda (22) & -14 & $299 \pm 3 \cdot 0^{c}$ & 63 & $-11.9 \pm 1 \cdot 1^{\mathrm{a}}$ & $6 \cdot 28 \pm 0.06^{a}$ & $2 \pm 0 \cdot 3^{\mathrm{a}}$ \\
\hline
\end{tabular}

Values are mean \pm s.e.m.

$a, b, c$ indicate that difference between mean value for site indicated and the value for the site shown on the line above is statistically significant with respective probabilities of $P<0.001, P<0.01$ and $P<0.05$.

*No. in parentheses corresponds to region shown in Fig. 1, Jones et al. (1984).

$\dagger$ Measured on whole blood.

†rom Jones (1987).

$\$ C$ Calculated as the difference between the measured osmolality and the sum of molarities of inorganic ions (excluding bicarbonate) multiplied by 0.91 , the osmotic coefficient used by Levine \& Marsh (1971).

\section{Results}

\section{Fluid reabsorption (Table 1)}

Spermatocrits (Jones, 1987) showed that $87 \%$ of the fluid leaving the rete testis was reabsorbed by the ductuli efferentes $(P<0 \cdot 001)$. The caput and corpus epididymidis respectively reabsorbed $78 \%(P<0.001)$ and $27 \%(P<0.01)$ of the fluid which entered them, but this only accounts for $10 \%$ and $1 \%$ of the fluid which left the testis.

\section{Osmolality (Table 1)}

The osmolality of blood plasma and rete testis fluid was much the same and the fluid reabsorption in the ductuli efferentes did not significantly affect the osmolality of the luminal milieu. There was an increase in osmolality of the luminal fluid in the caput epididymidis $(P<0.001)$, the fluid remained hyperosmotic in the corpus epididymidis and then reduced $(P<0.05)$ to about the same osmolality as blood plasma in the cauda epididymidis.

\section{Potential difference (Table 1)}

The mean electrical potential at the proximal end of the epididymis was $-7.9 \mathrm{mV}$ (lumen negative to the bathing medium) and the caput and corpus epididymidis appear to be isopotential throughout. There was an increase in the potential difference to $-11.9 \mathrm{mV}$ in the cauda epididymidis $(P<0.001)$.

\section{pH and bicarbonate concentration (Table 1)}

The $\mathrm{pH}$ of rete testis fluid was about neutral and much lower $(P<0.001)$ than blood. The luminal fluid was acidified $(P<0.001)$ as it passed through the sperm ducts to the cauda epididymidis. Although the bicarbonate concentration in blood was about three times the concentration in rete testis fluid $(P<0.001)$ bicarbonate was clearly the main buffer in rete testis fluid 
because when exposed to atmospheric conditions, the $\mathrm{pH}$ of rete testis fluid rose from $7 \cdot 0$ to more than 8.0 in $10 \mathrm{~min}$. The bicarbonate concentration of the luminal fluid was lower in the cauda epididymidis than in the rete testis $(P<0.001)$, but caudal fluid was not as sensitive to exposure to air as was rete testis fluid.

\section{Sodium (Table 2)}

Intraluminal concentrations of sodium were lower than in blood plasma $(P<0.001)$. There was a net active reabsorption of sodium from the ductuli efferentes $(P<0.001)$ and caput $(P<0.001)$ and corpus $(P<0.01)$ epididymidis. The combined effect of some sodium transport out of the duct and fluid transport into the duct caused a reduction in sodium concentration from $77.4 \mathrm{~mm}$ in the distal corpus to $51.2 \mathrm{~mm}$ in the distal cauda epididymidis $(P<0.001)$. It was considered that there was a gradual reduction in sodium concentration along the duct and that this would be demonstrated by an appropriate statistical test of significance, or by studying more animals. Consequently, the former possibility was tested using polynomial coefficients (Fisher \& Yates, 1957) to partition the total variance between sample sites into individual degrees of freedom (Snedecor \& Cochran, 1967). In this test nearly all of the variance partitioned into the component, showing that there is a gradual reduction in sodium concentration along the duct $(P<0.001)$.

\section{Potassium (Table 2)}

Intraluminal concentrations of potassium were higher than in blood plasma $(P<0.001)$. Potassium was reabsorbed passively from the ductuli efferentes $(P<0.001)$ and caput epididymidis $(P<0.001)$. Potassium in the reabsorbate was approximately isomolar with its luminal concentration in the ductuli efferentes, but hypomolar with its luminal concentration in the caput epididymidis. Consequently, there was an increase in the intraluminal concentration of potassium from $11.4 \mathrm{~mm}$ in the proximal caput to $23.2 \mathrm{~mm}$ in the distal caput epididymidis $(P<0.01)$. Fluid reabsorption in the corpus epididymidis caused a further increase in the luminal concentration of potassium $(P<0.05)$. Subsequently, potassium was actively transported into the lumen of the cauda epididymidis $(P<0.001)$ causing an increase in the luminal concentration from $30.3 \mathrm{~mm}$ in the distal corpus to $56.4 \mathrm{~mm}$ in the distal cauda epididymidis $(P<0.001)$.

\section{Chloride (Table 2)}

Chloride levels were higher in the rete testis fluid than in blood plasma $(P<0.001)$. In the ductuli efferentes it was passively reabsorbed $(P<0.001)$. Chloride in the reabsorbate was hypermolar to its luminal concentration so that there was a decrease in mean luminal concentration from $130.2 \mathrm{~mm}$ in the rete testis to $94.0 \mathrm{~mm}$ in the proximal caput epididymidis $(P<0.001)$. It was also passively reabsorbed in the caput $(P<0.001)$ and corpus $(P<0.01)$ epididymidis. Then, it was actively secreted into the cauda epididymidis $(P<0.01)$ causing an increase in mean intraluminal concentration from $91.0 \mathrm{~mm}$ in the distal corpus to $128.8 \mathrm{~mm}$ in the distal cauda epididymidis $(P<0.001)$.

\section{Calcium (Tables 2 and 3)}

About half of the calcium in blood was removed by filtration $(P<0.001)$. Nevertheless, the concentration of unfiltered $(P<0.05)$ as well as total calcium $(P<0.001)$ was greater in blood than in rete testis fluid. Low levels of luminal calcium were maintained by active reabsorption in the ductuli efferentes $(P<0.001)$. 


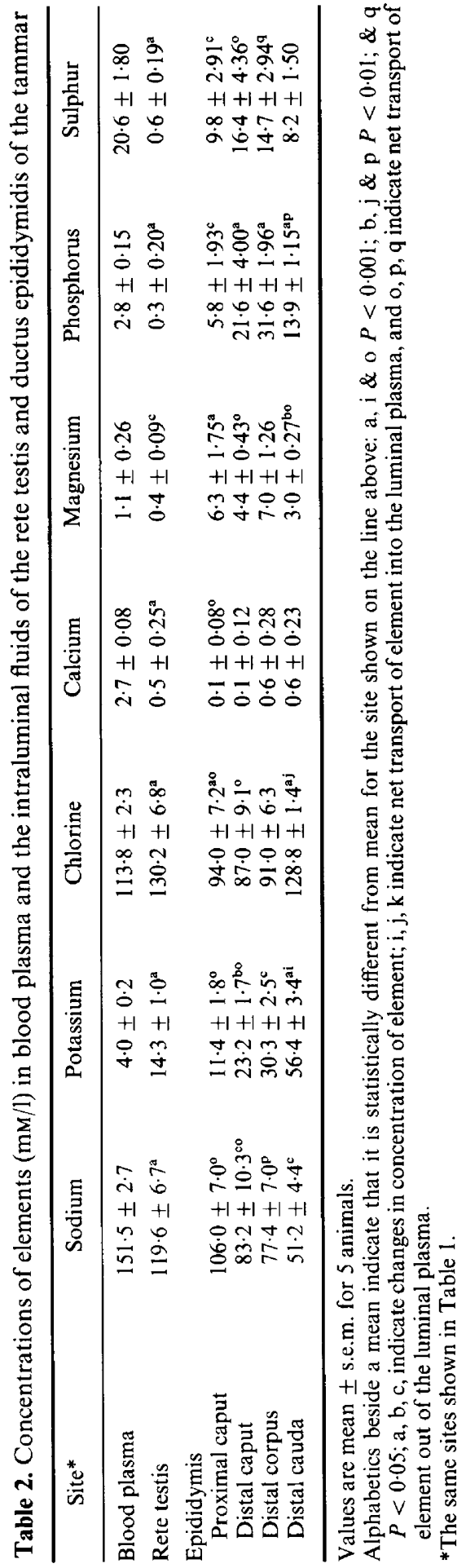


Table 3. The concentration of elements (mM) in filtered or unfiltered tammar fluids

\begin{tabular}{|c|c|c|c|c|}
\hline & & $\begin{array}{l}\text { Blood } \\
\text { plasma }\end{array}$ & $\begin{array}{l}\text { Rete testis } \\
\text { plasma }\end{array}$ & $\begin{array}{l}\text { Plasma from } \\
\text { distal cauda } \\
\text { epididymidis }\end{array}$ \\
\hline Calcium & $\begin{array}{l}\text { Unfiltered } \\
\text { Filtrate }\end{array}$ & $\begin{array}{l}2.7 \pm 0.08 \\
1.3 \pm 0.17^{*}\end{array}$ & $\begin{array}{l}0.5 \pm 0.25 \\
0.6 \pm 0.13\end{array}$ & $\begin{array}{l}0.6 \pm 0.23 \\
0.4 \pm 0.16\end{array}$ \\
\hline Magnesium & $\begin{array}{l}\text { Unfiltered } \\
\text { Filtrate }\end{array}$ & $\begin{array}{l}1 \cdot 1 \pm 0 \cdot 26 \\
0.2 \pm 0 \cdot 11^{*}\end{array}$ & $\begin{array}{r}0.4 \pm 0.09 \\
0.19 \pm 0.09\end{array}$ & $\begin{array}{l}3.0 \pm 0.27 \\
2.8 \pm 0.53\end{array}$ \\
\hline Phosphorus & $\begin{array}{l}\text { Unfiltered } \\
\text { Filtrate }\end{array}$ & $\begin{array}{l}2.8 \pm 0.15 \\
1 \cdot 0 \pm 0.14 \dagger\end{array}$ & $\begin{array}{l}0 \cdot 3 \pm 0 \cdot 20 \\
0 \cdot 6 \pm 0 \cdot 26\end{array}$ & $\begin{array}{l}13.9 \pm 1 \cdot 15 \\
11.9 \pm 1.48\end{array}$ \\
\hline Sulphur & $\begin{array}{l}\text { Unfiltered } \\
\text { Filtrate }\end{array}$ & $\begin{aligned} 20 \cdot 6 & \pm 1 \cdot 81 \\
1 \cdot 1 & \pm 0 \cdot 11 \dagger\end{aligned}$ & $\begin{array}{l}0.6 \pm 0.19 \\
0.9 \pm 0.17\end{array}$ & $\begin{array}{l}8.2 \pm 1.50 \\
4.4 \pm 0.69\end{array}$ \\
\hline
\end{tabular}

Values are mean \pm s.e.m. for 5 tammars except as indicated.

${ }^{*} P<0.05$ compared with unfiltered value.

$\dagger P<0.001$ compared with unfiltered value.

\section{Magnesium (Table 2)}

About $80 \%$ of the magnesium in blood was removed by filtration $(P<0.05)$. Consequently, although the total concentration of magnesium was greater in blood than rete testis fluid $(P<0.05)$ the concentrations of unfiltered element were much the same in the two fluids. The reabsorption of fluid by the ductuli efferentes caused an increase in the mean luminal concentration of magnesium from $0.35 \mathrm{~mm}$ in the rete testis to $6.30 \mathrm{~mm}$ in the proximal caput epididymidis $(P<0.001)$. It was passively reabsorbed in the caput $(P<0.001)$ and cauda $(P<0.001)$ epididymidis. The reabsorption in the cauda epididymidis caused a reduction in mean intraluminal concentration from $7.0 \mathrm{~mm}$ in the distal corpus to $3.0 \mathrm{~mm}$ in the distal cauda epididymidis $(P<0.01)$.

\section{Phosphorus (Tables 2 and 3)}

More than half the phosphorus in blood was removed by filtration $(P<0.001)$. Consequently, although the total concentration of phosphorus was higher in blood plasma than in rete testis fluid $(P<0.001)$ the concentrations of phosphorus in filtrates of both fluids was much the same.

Due to the reabsorption of fluid from the ducts, phosphorus was concentrated in the ductuli efferentes $(P<0.05)$ and caput epididymidis $(P<0.001)$ from a mean value of $0.3 \mathrm{~mm}$ in rete testis fluid to $21.6 \mathrm{~mm}$ in fluid from the distal caput epididymidis. However, there was a net loss of phosphorus $(P<0.01)$ from the luminal plasma of the cauda epididymidis causing a decrease in its concentration to $13.9 \mathrm{~mm}$ in the distal cauda epididymidis $(P<0.001)$.

\section{Sulphur (Tables 2 and 3)}

About $95 \%$ of sulphur in blood plasma was removed by filtration $(P<0.001)$. Consequently, although the total concentration of sulphur was higher in blood plasma than in rete testis fluid $(P<0.001)$, the concentrations of free sulphur in filtrates of both fluids were much the same. Sulphur was concentrated in the luminal plasma by reabsorption of fluid out of the ductuli efferentes $(P<0.05)$ and this level was maintained by transport of sulphur from the luminal plasma in the caput $(P<0.001)$ and corpus $(P<0.05)$ epididymidis.

\section{Discussion}

As proposed in the 'Introduction' these and our earlier studies (Jones, 1987) are the first of their 
type to distinguish the functions of the ductuli efferentes from the initial segment of the epididymis. They show that the ductuli efferentes reabsorb most of the fluid $(87 \%)$ and half the protein leaving the testis. It is considered that the transport mainly involves the coupling of water and active solute transport (Diamond, 1971; Hill, 1975; Jones \& Jurd, 1987), particularly the transport of sodium and potassium at about the same concentrations as they are present in the luminal fluid. Calcium concentrations were also maintained in the ductuli, but fluid reabsorption by the ductuli caused an increase in the intraluminal concentrations of magnesium, and phosphorus and sulphur containing compounds.

Earlier work (Jones et al., 1984) indicated that the caput epididymidis of the tammar corresponds to the initial segment described by Benoit (1926) and that spermatozoa begin to develop the capacity for motility in this segment. The results described in this report indicate that the segment plays quite a different role than the ductuli efferentes in regulating the intraluminal milieu. Although the segment reabsorbs $50 \%$ of the fluid leaving the ductuli efferentes this is only $11 \%$ the amount reabsorbed by the ductuli. Further, while sodium and potassium are both reabsorbed in the segment potassium is transported in the ductuli efferentes hypomolar to its luminal concentration. Also, magnesium and compounds containing sulphur are reabsorbed in the caput epididymidis and it is considered that a more sensitive measure of calcium concentration would show that it is also reabsorbed in the caput. The concentration of phosphorus is increased by a factor of 3.7 times, indicating that phosphorus containing compounds must be secreted into the duct as well as being concentrated by fluid absorption. This is consistent with the estimates of osmotic difference, which show that organic compounds must be secreted into the caput, and work on proteins (Jones, 1987) which showed that the caput is highly secretory.

Jones et al. (1984) indicated that spermatozoa 'mature' soon after they enter the corpus epididymidis of the tammar. Nevertheless, compared to the caput epididymidis the corpus is relatively inactive in terms of net fluid and ion transport. The fluid reabsorption is associated with sodium transport and results in an increase in the intraluminal concentration of potassium and compounds containing phosphorus. There is also a net removal of sulphur-containing compounds from the luminal plasma and this is correlated with a net loss of protein from the plasma (Jones, 1987).

Jones et al. (1984) indicated that spermatozoa are 'mature' when they enter the cauda epididymidis of the tammar and that the structure of the duct mucosa indicates that it is adapted more for solute transport than are proximal regions of the duct. The studies described in this report confirm that there is considerable ion transport, but there is little net fluid transport in the region. In brief, this and our earlier report (Jones, 1987) show that there is a decrease in epididymal plasma concentrations of sodium, magnesium, phosphorus and protein, whilst there is an increase in the concentration of chloride and potassium. The work also shows that most of the changes involve active transport across the duct mucosa.

The findings described in this report on the composition of rete testis fluid in the tammar are in agreement with earlier work in which the fluid was collected by cannulation (Setchell, 1970). The findings on the tammar's epididymis are also in general agreement with those for other mammals which have been studied (see 'Introduction'). The most distinctive features of the tammar epididymis are the high concentrations of magnesium and chloride, the low concentrations of sulphur and phosphorus and the low osmotic difference. Considering the maximum osmotic difference in fluids from the epididymidis in the rat ( $224 \mathrm{mosmol} / \mathrm{kg}$; calculated from Jenkins et al., 1980) and tammar ( $130 \mathrm{mosmol} / \mathrm{kg})$ and that the concentrations of phosphorus and sulphur in the rat reach 3 times and 2 times respectively those in the tammar, it is concluded that organic compounds exist in lower concentrations in the epididymidis of the tammar than in that of the rat and other eutherians. As chloride is the major inorganic anion contributing to the osmolality of epididymal plasma, the movement of chloride in and out of the duct probably corresponds to the accumulation and removal of organic compounds. The removal of organic compounds from the cauda epididymidis probably explains why the osmotic difference for the tammar is only $63 \mathrm{mosmol} / \mathrm{kg}$. 
We thank Dr L. A. Hinds and Dr C. H. Tyndale-Biscoe, CSIRO, Division of Wildlife and Rangelands Research, for help and advice; the Australian Research Grants Scheme and the Senate Research Committee, University of Newcastle, for financial support.

\section{References}

Bedford, J.M. (1975) Maturation, transport and fate of spermatozoa in the epididymis. In Handbook of Physiology, Section 7, Volume 3. Male Reproduction, pp. 303-317, Eds R. O. Greep \& E. B. Astwood. American Physiological Society, Washington D.C.

Benoit, J. (1926) Recherches anatomiques, cytologiques et histolphysiologiques sur les voies excretices du testicule, chez les mammiferes. Archs Anat. Histol. Embryol. 5, 173-412.

Crabo, B.O. (1965) Studies on the composition of epididymal content in bulls and boars. Acta vet. scand. 6, Suppl. 5, 1-94.

Crabo, B. \& Gustafson, B. (1964) Distribution of sodium and potassium and its relation to sperm concentration in the epididymal plasma of the bull. $J$. Reprod. Fert. 7, 337-345.

Diamond, J.M. (1971) Standing-gradient model of fluid transport in epithelium. Fedn Proc. Fedn Am. Socs exp. Biol. 30, 6-13.

Djakiew, D. \& Jones, R.C. (1983) Sperm concentration, fluid transport and secretion and absorption of protein in the epididymis of the echidna, Tachyglossus aculeatus. J. Reprod. Fert. 68, 445-456.

Fisher, R.A. \& Yates, F. (1957) Statistical Tables for Biological, Agricultural and Medical Research, 5th edn, p. 90 . Oliver \& Boyd, London.

Hill, A.E. (1975) Solute-solvent coupling in epithelia: a critical examination of the standing-gradient osmotic flow theory. Proc. R. Soc., Lond. B 190, 99-114.

Jenkins, A.D., Lechene, C.P. \& Howards, S.S. (1980) Concentrations of seven elements in the intraluminal fluids of the rat seminiferous tubules, rete testis and epididymis. Biol. Reprod. 23, 981-987.

Jones, R.C. (1980) Luminal composition and maturation of spermatozoa in the genital duct of the African elephant, Loxodonta africana. J. Reprod. Fert. 60, 87-93.

Jones, R.C. (1987) Changes in protein composition of the luminal fluids along the epididymis of the tammar, Macropus eugenii. J. Reprod. Fert. 80, 193-199.

Jones, R.C. \& Jurd, K.M. (1987) Structural differentiation and fluid reabsorption in the ductuli efferentes testis of the rat. Aust. J. biol. Sci. 40, 79-90.

Jones, R.C., Hinds, L.A. \& Tyndale-Biscoe, C.H. (1984) Ultrastructure of the epididymis of the tammar, Macropus eugenii and its relationship to sperm maturation. Cell Tissue Res. 237, 525-535.
Levine, N. \& Kelly, H. (1978) Measurement of pH in rat epididymis in vivo. J. Reprod. Fert. 52, 333-335.

Levine, N. \& Marsh, D.J. (1971) Micropuncture studies of the electrochemical aspects of fluid and electrolyte transport in individual seminiferous tubules, the epididymis and the vas deferens in rats. J. Physiol., Lond. 213, 557-570.

Morel, F., Roinel, N. \& Le Grimellec, C. (1969) Electron probe analysis of tubular fluid composition. Nephron 6, 350-364.

Nicander, L. \& Glover, T.D. (1973) Regional histology and fine structure of the epididymal duct in the golden hamster (Mesocricetus auratus). J. Anat. 114, 347-364.

Orgebin-Crist, M.C. (1975) Endocrine control of the development and maintenance of sperm fertilizing ability in the epididymis. In Handbook of Physiology. Vol. 5, Sect. 7, Endocrinology, pp. 319-338. Eds R. O. Greep \& D. W. Hamilton. American Physiological Society, Washington D.C.

Reid, B.L. \& Cleland, K.W. (1957) The structure and function of the epididymis. I. The history of the rat epididymis. Aust. J. Zool. 5, 223-246.

Rick, R., Horster, M., Dörge, A. \& Thurau, K. (1977) Determination of electrolytes in small biological fluid samples using energy dispersive $\mathrm{X}$-ray microanalysis. Pflügers Archiv. ges. Physiol. 369, 95-98.

Scott, T.W., Wales, R.G., Wallace, J.C. \& White, I.G. (1963) Composition of ram epididymal and testicular fluid and the biosynthesis of glycerylphosphorylcholine by the rabbit epididymis. J. Reprod. Fert. 6, 49-59.

Setchell, B.P. (1970) Fluid secretion by the testes of an Australian marsupial Macropus eugenii. Comp. Biochem. Physiol. 36, 411-414.

Snedecor, G.W. \& Cochran, W.G. (1967) Statistical Methods, 6th edn, pp. 460-471. Iowa State University Press, Ames.

Tuck, R.R., Setchell, B.P., Waites, G.M.H. \& Young, J.A. (1970) The composition of fluid collected by micropuncture and catheterization from the seminiferous tubules and rete testis of rats. Pfügers Archiv. ges. Physiol. 318, 225-243.

Wales, R.G., Wallace, J.C. \& White, I.G. (1966) Composition of bull epididymal and testicular fluid. $J$. Reprod. Fert. 12, 139-144.

Received 24 April 1987 